\title{
Summary and Prospects
}

\author{
Robert P. HEANEY \\ John A. Creighton University, Omaha, Nebraska, U.S.A.
}

The topic of this symposium is "Calcium Metabolism and Aging," and the aegis under which we have operated is the U.S.-Japan Malnutrition Panel. Taken together these involve a presumption that calcium-malnutrition may be a problem in an aging population. We have looked at the evidence from a variety of viewpoints, and the scientific verdict, if we had to come to one now, would be: "Probably-but not yet proven." We have learned a lot over the past few years, and the evidence points in the direction of an important role for dietary calcium in the maintenance of bone health throughout life, but there are nagging uncertainties and puzzling exceptions.

We have asked whether the recommended dietary allowance (RDA) should be raised, and we have noted that the NIH Consensus Conference (1) did choose to recommend increased calcium intake, particularly in estrogen-deprived, postmenopausal women. Once again, the evidence is incomplete from a scientific standpoint, but I sensed general agreement in this meeting with the following strategic logic.

If we raise the RDA and it turns out we are wrong, we have done little or no harm; if we fail to raise it until we have better data, and it turns out later that raising it was the right thing to have done, then we will have withheld a benefit from our population, and thereby done a great deal of harm.

On balance, this analysis seems to favor increasing the RDA now. We have noted that calcium intake is often well below the RDA, and one might wonder whether the RDA makes any difference. I believe it does, but only indirectly, insofar as it influences public nutritional policy, governmental supported food programs, and food fortification practices.

We have noted that there are a number of pressing issues to which workers in both our countries should address themselves. One is the matter of the role of calcium intake in achieving peak adult bone mass. Good bone mass measurement technology now exists, and this issue needs to be addressed on a broad front. It is susceptible to a reasonably clear "yes" or "no" answer, and either answer has far-reaching implications for global nutritional policy. Another issue is the need for better population-based studies, both of the prevalence of different types of fracture, and of the relation between calcium intake and fracture, and between calcium intake and bone mass in the middle years of life and beyond. In such studies, however, we now recognize the importance of measuring vitamin $\mathrm{D}$ status and of controlling for hormonal, excercise, and other nutrient factors. Future studies without such controls are not likely to help us out of our current perplexity.

Finally I have been impressed with the emerging importance of vitamin $\mathbf{D}$ in this problem. Despite the fact that vitamin D was not explicitly included in the title of the symposium, at least four papers presented at this meeting forced us to confront the existence of inadequate $\mathrm{D}$ status in osteoporotics, particularly here in Japan, and I think it is interesting to note how rapidly this issue has evolved. Three years ago, several of us in this room were involved in a project for the American Society of Clinical Nutrition, dealing with exactly the same topic as this symposium, and at that time we concluded that, by and large, vitamin D status was adequate in the elderly, at least in the U.S. (2). If we had reconvened the panel today, I don't believe we could still hold to that opinion. Inadequate D status of susceptible populations holds the prospect of dissipating some of the current ambiguity surrounding the role of calcium in osteoporosis and the questions of calcium requirement and allowance. More 
work needs to be done in this important area.

In conclusion, it seems safe to say that, while we have come far in our understanding of calcium metabolism in aging, it is clear that we still have far to go. Thank you.

\section{REFERENCES}

1) Consensus Conference (1982): Osteoporosis. JAMA, 252, 799-802.

2) Parfitt, M.B., Gallagher, J.C., Heaney, R.P., Johnson, C.C., Neer, R., and Whedon, G.D. (1982): Vitamin $\mathrm{D}$ and bone health in the elderly. Am. J. Clin. Nutr., 36, 1014-1031. 